\title{
PERBANDINGAN FAKTOR TEKNIS DESAIN KAPAL BANTUAN DENGAN KAPAL LOKAL $\leq 5$ GT DI KABUPATEN CILACAP JAWA TENGAH
}

\author{
Technical Factor Design Comparison of Fishing Vessel Grant with Local Vessel $\leq 5 G T$ in \\ Cilacap Regency, Central Java
}

\author{
Oleh: \\ Rois Syarif Qoidhul Haq ${ }^{1 *}$, Mohammad Imron², Budhi Hascaryo Iskandar³ \\ ${ }^{1}$ Departemen Pemanfaatan Sumberdaya Perikanan, Fakultas Perikanan dan Ilmu Kelautan, Institut Pertanian Bogor, Bogor. \\ roislpdp112@gmail.com \\ 2 Departemen Pemanfaatan Sumberdaya Perikanan, Fakultas Perikanan dan Ilmu Kelautan, Institut Pertanian Bogor, Bogor. \\ mohammad.imron@gmail.com \\ 3 Departemen Pemanfaatan Sumberdaya Perikanan, Fakultas Perikanan dan Ilmu Kelautan, Institut Pertanian Bogor, Bogor. \\ bhascaryo.iskandar@gmail.com \\ *Korespondensi: roislpdp112@gmail.com
}

Diterima: 24 Maret 2020; Disetujui: 24 Juli 2020

\begin{abstract}
Government-grant fiberglass fishing vessels with gross tonnage (GT) $\leq 5$ in Cilacap Regency (KM. Nelayan 2018) were renovated by local fishermen before it could be used. Renovations were carried out by changing some details in technical design which are not the same as fishing vessels used by fishermen. This study aims to identify and compare technical factors in the design of $\leq 5 G T$ granted and local fishing vessels in Cilacap Regency. Data were collected by measuring main dimensions as well as observing hull and bow shapes, general arrangement and also working areas. Those data were then compared as follows. The ratio of $L / D$ and $L / B$ of granted vessels are 8.96 and 13.33 which are between the ranges of local vessels' ratio making up 7.72-9.20 for $L / D$ and 12.9214.11 for $L / B$. The value of $B / D$ of granted vessels is smaller than its counterparts (1.49 compared to 1.51-1.71). The hull shape of granted fishing vessels and local vessels are both u-bottom. Similarities are also found in the bow and the stern shapes, which are raked bow and transom stern. The bow height of granted vessels is $1.9 \mathrm{~m}$, significantly higher than the average of local vessels which is only $1.34 \mathrm{~m}$. The height of the engine mount at the stern of granted vessels is also higher than local ones, as 56 compared to $52 \mathrm{~cm}$. Generally, the general arrangement and working areas of both vessels do not show significant differences.
\end{abstract}

Keywords: feature, fiberglass fishing vessel, technical factor design

\section{ABSTRAK}

Kapal fiberglass bantuan pemerintah yaitu KM. Nelayan 2018 dengan gross tonnage (GT) $\leq 5$ di Kabupaten Cilacap direnovasi oleh nelayan setempat sebelum dapat digunakan. Renovasi yang dilakukan terkait pada detail faktor teknis desain, dikarenakan tidak sesuai dengan kapal yang biasa digunakan oleh mereka. Penelitian ini bertujuan untuk mengidentifikasi dan membandingkan faktor teknis pada desain kapal bantuan dan kapal lokal $\leq 5 \mathrm{GT}$ yang ada di Kabupaten Cilacap. Pengambilan data dilakukan dengan mengukur dimensi utama dan mengamati bentuk kasko, bentuk linggi, tata letak serta working area kapal. Data hasil identifikasi tersebut kemudian dibandingkan. Hasil perbandingan menunjukkan bahwa rasio dimensi utama L/D dan L/B kapal bantuan berturutturut adalah 8,96 dan 13,33 . Nilai tersebut berada di kisaran rasio dimensi utama kapal lokal yaitu 7,72-9,20 untuk L/D dan 12,92-14,11 untuk L/B. Selanjutnya, nilai B/D kapal bantuan lebih kecil dari 
kisaran rasio kapal lokal (1,49 dibandingkan dengan 1,51-1,71). Kasko kapal bantuan dan lokal memiliki bentuk serupa yaitu u-bottom. Kesamaan bentuk juga ditemukan pada linggi haluan dan linggi buritan yang berbentuk raked bow dan transom stern. Ketinggian linggi haluan kapal bantuan mencapai $1,90 \mathrm{~m}$, nilai tersebut lebih tinggi dari rata-rata kapal lokal yaitu 1,34 m. Ketinggian dudukan mesin pada linggi buritan kapal bantuan juga lebih tinggi dibandingkan dengan rata-rata kapal lokal yaitu $56 \mathrm{~cm}$ dibandingkan dengan $52 \mathrm{~cm}$. Secara umum, general arrangement dan working area kedua kapal tidak menunjukkan perbedaan yang signifikan.

Kata kunci: corak, faktor teknis desain, kapal perikanan fiberglass

\section{PENDAHULUAN}

Upaya pemerintah Republik Indonesia dalam memberikan kapal bantuan kepada nelayan masih terus dioptimalkan. Direktur Jenderal Perikanan Tangkap (DJPT) pada tahun 2019 mengumumkan bahwa pada tahun 2018 sebanyak 562 kapal bantuan berukuran $\leq 5 \mathrm{GT}$ (gross tonnage) telah diberikan kepada koperasi nelayan di berbagai daerah pesisir di Indonesia. Bantuan dengan ukuran yang lebih kecil ini diharapkan lebih dapat diterima oleh nelayan, mengingat bantuan-bantuan kapal sebelumnya terhambat oleh faktor penerimaan oleh nelayan sebagai pengguna kapal (Subagyo 2019)

Terdapat beberapa faktor yang menjadi pertimbangan nelayan dalam menggunakan kapal bantuan, diantaranya adalah faktor ekonomi, sosial dan kelembagaan (Mira 2015; Kadir et al. 2016). Faktor teknis yaitu desain kapal yang tidak sesuai dengan karakteristik daerah atau kebiasaan nelayan setempat juga menjadi sebuah pertimbangan (Bangun et al. 2017; Putra 2019). Sebagaimana diketahui bahwa daerah pesisir di Indonesia memiliki karakteristik lingkungan, sumber daya alam dan manusia yang berbeda-beda (Djunaedi dan Basuki 2002; Juniarta et al. 2013; Lautetu et al. 2019; Rukayah dan Thaba 2018). Perbedaan tersebut menjadi kendala pemerintah dalam membuat kapal bantuan yang sesuai dengan kebiasaan nelayan lokal yang beragam. Hal ini dikarenakan kapal bantuan berbahan dasar fiberglass umumnya dibuat dengan satu desain yang sama untuk berbagai daerah mengikuti kaidah naval architecture. Sementara itu, kapal lokal dibuat berdasarkan pengalaman turun temurun, tanpa perencanaan gambar desain, kontruksi dan perhitungan naval architecture (Susanto et al. 2011; Trimulyono et al. 2015).

Kabupaten Cilacap mendapat tujuh kapal bantuan yang dilengkapi dengan alat tangkap gill net. Ketujuh kapal bantuan diberi nama KM Nelayan 2018 dengan masing-masing bernomor urut 393 sampai 399. Akan tetapi ketujuh kapal bantuan tersebut belum dimanfaatkan dengan baik. Hal ini dikarenakan kapal bantuan dianggap tidak sesuai dengan kapal yang biasa digunakan oleh nelayan setempat untuk penangkapan menggunakan alat tangkap gill net, meskipun desain keduanya menunjukkan kemiripan. Salah satunya adalah dudukan mesin kapal bantuan yang lebih tinggi daripada kapal lokal. Hal ini akan berakibat pada kekuatan dorong mesin yang berkurang dan menyebabkan kecepatan kapal menurun (Kilmanun 2012).

Sebagai usaha untuk memanfaatkan kapal bantuan yang sudah diberikan agar tetap terpakai, nelayan melakukan renovasi pada kapal bantuan dengan merubah desainnya agar lebih menyerupai kapal lokal. Perubahan dilakukan pada beberapa bagian meliputi (1) linggi kapal: penurunan tinggi dudukan mesin pada linggi buritan kapal, (2) general arrangement kapal: penambahan sekat air pada reserve buoyancy buritan, pengurangan kemiringan reserve buoyancy haluan kapal sebagai working area nelayan, penambahan dasar ganda dan juga penebalan bibir kapal.

Selain melakukan renovasi, nelayan Cilacap juga masih perlu beradaptasi dengan kapal bantuan. Adaptasi nelayan dilakukan karena terdapat beberapa faktor teknis desain kapal bantuan yang tidak sesuai dengan kapal lokal namun upaya renovasi sulit dilakukan. Ketidaksesuaian tersebut meliputi dimensi utama dan tinggi linggi haluan kapal bantuan yang ukurannya lebih besar daripada kapal lokal pada umumnya.

Secara umum, komponen-komponen kapal bantuan yang perlu untuk direnovasi dan diadaptasi oleh nelayan merupakan faktor teknis desain yang dapat mempengaruhi karakteristik sebuah kapal. Hal ini sesuai dengan hasil dari beberapa kajian yang menyebutkan bahwa faktor teknis seperti rasio dimensi utama, bentuk linggi dan bentuk kasko dapat mempengaruhi performa kapal (Novita dan Iskandar 2008; Utomo 2010, Nahdyah et al. 2014; Bangun et al. 2017). 
Selanjutnya, adanya proses renovasi dan adaptasi yang masih harus dilakukan oleh nelayan lokal menegaskan bahwa perbedaan desain antara kapal bantuan dan kapal lokal perlu diminimalisir untuk meningkatkan keberhasilan progam kapal bantuan. Sayangnya, perbedaan faktor teknis desain pada kedua jenis kapal belum teridentifikasi dengan baik, sehingga upaya perbaikan belum dapat dilakukan. Oleh karena itu, sebagai langkah awal, penelitian ini dilakukan untuk mengidentifikasi dan membandingkan faktor teknis pada desain kapal bantuan dan kapal lokal $\leq 5 \mathrm{GT}$ beralat tangkap gill net yang ada di Kabupaten Cilacap. Harapannya, informasi yang diperoleh dari penelitian ini akan memberikan manfaat bagi pemerintah sebagai rekomendasi detail faktor teknis kapal yang ada di Kabupaten Cilacap.

\section{METODE}

Jumlah kapal penangkap ikan tradisional $\leq 5 \mathrm{GT}$ dengan alat tangkap gill net (oleh nelayan lokal di Kabupaten Cilacap biasa disebut dengan cirang) adalah sebanyak 1.332 unit yang tersebar di 5 kecamatan. Dari jumlah tersebut, diambil 10 sampel kapal, yang terdiri dari 8 kapal lokal dan 2 kapal bantuan. Sampel-sampel tersebut diambil dari Kecamatan Kampung Laut (4 sampel), Kecamatan Cilacap Selatan (2 sampel), Kecamatan Cilacap Utara (1 sampel), Kecamatan Kesugihan (1 sampel) dan Kecamatan Nusawungu (2 sampel). Pengambilan data dilaksanakan pada bulan November sampai Desember. Alat yang digunakan dalam pengambilan data meliputi alat tulis, penggaris, busur, roll meter, water pas, jangka sorong, tali kur, senter dan kamera.

Pengambilan data dilakukan dengan mengukur dimensi utama dan mengamati bentuk kasko, bentuk linggi, tata letak serta working area kapal. Form pengisian data disiapkan. Selanjutnya kapal diposisikan terlebih dahulu agar posisi kapal sejajar untuk dilakukan pengukuran. Kapal difoto dari tampak depan, samping, belakang dan atas. Setelah pengukuran dan pengamatan selesai, pemilik kapal diwawancara terkait pengalaman dalam teknik mengoperasikan alat tangkap, wilayah penangkapan, hasil tangkapan dan tempat pembuatan kapal serta pengetahuan tentang ciri khas maupun perbedaan kapal lokal Cilacap dengan daerah lain. Data kemudian diolah secara deksriptif. Data dimensi utama dianalisis menggunakan simulasi numerik dan dianalisis lanjutan terkait kesesuaiannya dengan kisaran nilai acuan yang diperoleh dari studi literatur.
Hasil identifikasi kemudian dibandingkan antara kapal bantuan dan kapal lokal nelayan. Masing-masing komponen diamati dan dibandingkan serta dianalisis secara deskriptif. Perbedaan faktor yang ada, kemudian didiskusikan dengan pihak galangan kapal pembuat kapal sampel dan juga Dinas Perikanan dan Kelautan yang ada di Kabupaten Cilacap untuk mengkonfirmasi hasil perbandingan identifikasi yang telah dilakukan.

Faktor teknis desain yang diteliti meliputi:

\section{Dimensi utama}

Pengukuran dimensi utama meliputi: (1) panjang total kapal (L); (2) lebar (B); dan (3) dalam (D). Data hasil pengukuran kemudian dihitung untuk mengetahui nilai rasio dimensi utama kapal. Rasio dimensi utama kapal menurut Fyson (1985) dapat diketahui dari hasil perbandingan L/B, L/D dan B/D.

\section{Bentuk linggi dan kasko kapal}

Bentuk linggi dan kasko kapal diamati dari kapal tampak samping dan depan. Hasil observasi kemudian diolah untuk mendapatkan lines plan kapal.

\section{General arrangement dan working area}

General arrangement merupakan tata letak dan gambaran bentuk umum kapal baik dari tampak atas, samping dan depan. Pada gambar ini juga akan ditampilkan working area (area kerja) pada kapal. Menurut Fyson (1985) aktivitas di atas kapal dibagi menjadi 5 area, yaitu (1) buritan, (2) samping, (3) ruang kemudi, (4) area kerja utama dan (5) haluan.

\section{HASIL}

\section{Dimensi Utama}

Hasil pengukuran dimensi utama digunakan untuk menghitung rasio dimensi utama meliputi perbandingan $\mathrm{L} / \mathrm{B}$, L/D dan B/D dan didapatkan hasil seperti yang dapat dilihat pada Gambar 1.

Berdasarkan hasil perhitungan rasio dimensi utama pada Gambar 1, menunjukkan bahwa nilai rasio L/B dan L/D pada kapal bantuan masih berada pada kisaran rasio kapal lokal. Berbeda dengan nilai rasio B/D, kapal bantuan memiliki nilai terkecil yaitu 1,49 , sedangkan rentang nilai kapal lokal adalah 1,511,71 . Semua nilai rasio yang didapat tidak melewati garis nilai maksimum dan minimum dari Iskandar dan Pudjiati (2008) untuk nilai yang sesuai dengan kapal beralat tangkap static. Artinya kapal bantuan masih memiliki rasio 
dimensi utama yang relatif sama dengan kapal lokal yang mengoperasikan alat tangkap gill net.

\section{Bentuk Linggi dan Kasko}

\section{Linggi haluan}

Berdasarkan hasil pengamatan, didapatkan bentuk linggi haluan kapal sebagaimana disajikan pada Gambar 2. Semua kapal fiberglass di Kabupaten Cilacap baik kapal bantuan maupun kapal lokal memiliki bentuk linggi haluan jenis raked bow. Jenis ini memiliki bentuk haluan yang lurus dan condong ke arah depan. Berdasarkan hasil kajian dari Bangun et al. (2017), jenis raked bow merupakan salah satu jenis yang umum digunakan nelayan di Indonesia selain jenis spon bow.

\section{Linggi buritan}

Bentuk linggi buritan dapat dilihat pada Gambar 3. Berdasarkan hasil pengamatan, bentuk linggi buritan kapal hanya memiliki satu bentuk yaitu jenis transom stern. Jenis ini memiliki ciri buritan yang tegak lurus dengan baseline kapal dan memiliki balok atau tempat dudukan mesin melintang pada buritan kapal. Putra (2019) juga menyampaikan bahwa kapal di Pelabuhan Perikanan Nusantara Brondong yang berasal dari Cilacap juga memiliki haluan raked bow dan bentuk buritan transom stern.

\section{Bentuk kasko}

Bentuk kasko pada umumnya dilakukan dengan mengamati bagian midship kapal, namun untuk kasus kapal fiberglass $\leq 5 \mathrm{GT}$ di Kabupaten Cilacap memiliki bentuk yang sama dari midship kapal sampai buritan. Pengamatan bentuk kasko selain dilakukan pada midship kapal, pengamatan juga dilakukan dengan melihat bagian buritan kapal. Berdasarkan hasil pengamatan, baik kapal bantuan maupun kapal lokal di Kabupaten Cilacap memiliki bentuk kasko kapal berbentuk u-bottom dikarenakan menyerupai bentuk "U" (Novita dan Iskandar 2008; Manopo et al. 2012). Bentuk kasko kapal dapat dilihat pada Gambar 4.

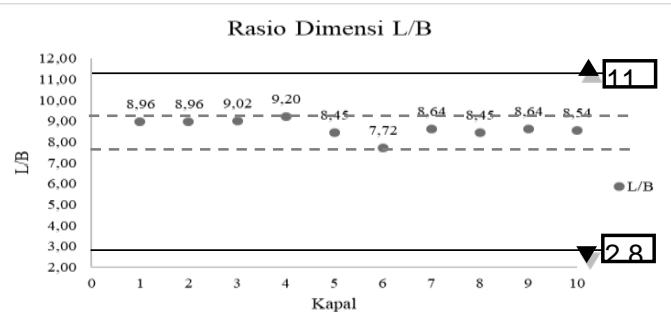

(A) L/B

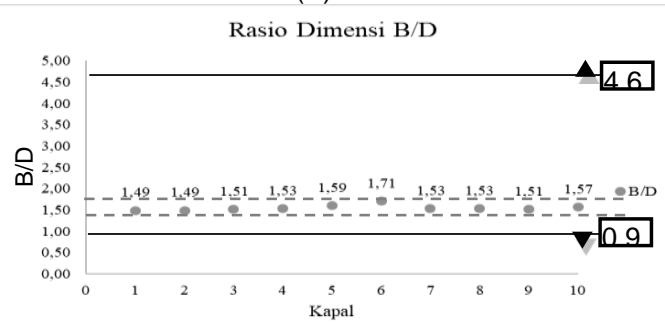

(C) $B / D$

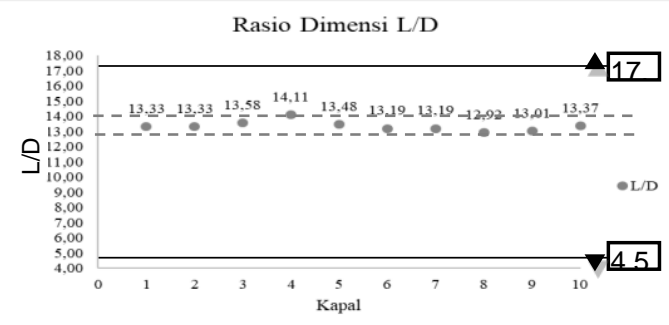

(B) L/D

Ket: Nilai Maximal kapal alat static aear Nilai Minimal kapal alat static gear (Iskandar dan Pudjiati 1995)

- - - Range data

Nama Kapal:

KM. Nelayan 2018 - 3986 Muncul Rejek 2 KM. Nelayan 2018 - 3947 Pamit Rukun Jaya 3 Sinar Kasih 8 Siti Usaha Jaya 4 Revanno Jaya 9 Sido Asih 5 Harbudi Jaya $01 \quad 10$ Cinta Sejati

Gambar 1 Rasio dimensi utama kapal
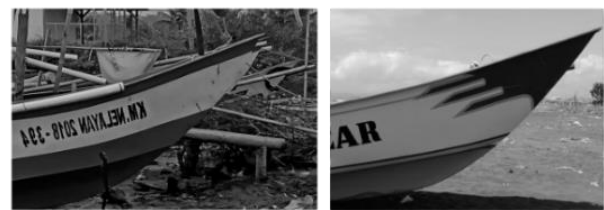

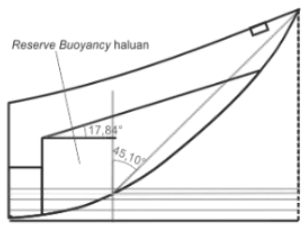

(a)

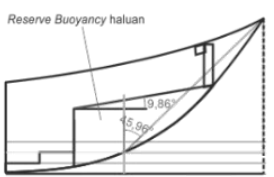

(b)

Gambar 2 Bentuk linggi kapal nelayan di Kab. Cilacap (a) Kapal bantuan KM. Nelayan 2018; (b) Kapal lokal 

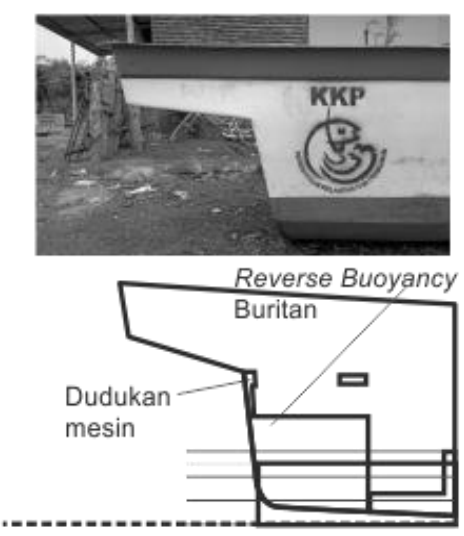

(a)

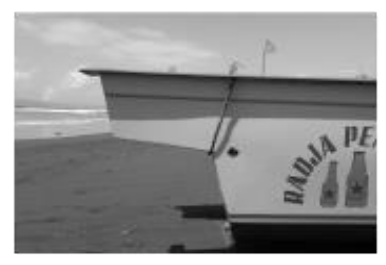

Reverse Buoyancy Buritan

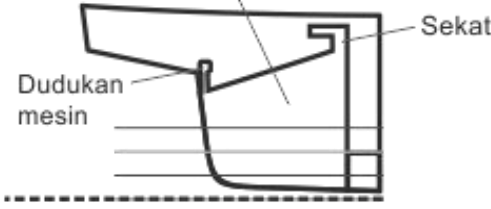

(b)

Gambar 3 Bentuk linggi buritan kapal nelayan di Kab. Cilacap

(a) Kapal bantuan KM. Nelayan 2018; (b) Kapal lokal
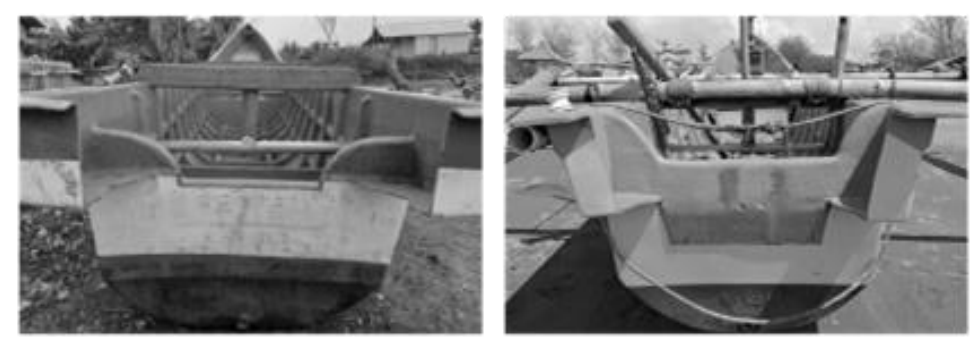

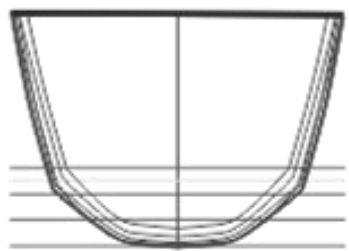

(a)

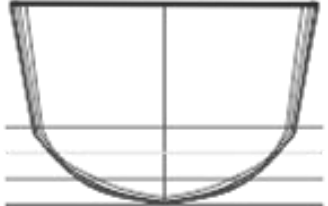

(b)

Gambar 4 Bentuk kasko kapal nelayan di Kab. Cilacap

(a) Kapal bantuan KM. Nelayan 2018; (b) Kapal lokal

\section{General Arrangement dan Working Area}

Setelah lines plan dibuat, kemudian desain kapal disempurnakan untuk mendapatkan gambar general arrangement dan working areanya (Gambar 5).

Kapal ukuran $\leq 5 \mathrm{GT}$ di Kabupaten Cilacap tidak memiliki dek. Alat tangkap dan cool box untuk penyimpanan hasil tangkapan diletakkan di dasar lambung kapal. Menurut Yulianto et al. (2013) kapal jenis ini akan lebih baik stabilitasnya jika alat tangkap dan hasil tangkapan diletakkan di bawah, untuk membuat titik beban kapal berada di bawah. Kapal dilengkapi dengan katir yang terbuat dari paralon berukuran 6-8 inci yang dilapisi fiberglass, sebagai penyeimbang kapal. Jarak antar gading pada kapal bantuan lebih rapat yaitu $\pm 40 \mathrm{~cm}$, sedangkan kapal lokal berjarak $\pm 50 \mathrm{~cm}$.
Gambar 5 menunjukkan bahwa tata letak dan area kerja kapal bantuan serta kapal lokal adalah sama. Bagian buritan (area nomor 1) adalah area kemudi kapal dan mesin kapal ditempelkan. Nahkoda kapal mengemudikan kapal dengan duduk atau berdiri pada palang melintang di atas reserve buoyancy buritan kapal. Pada bagian tengah kapal digunakan untuk meletakkan cool box yang berisi ikan hasil tangkapan. Samping cool box (area nomor 2) adalah area untuk nelayan berpindah dari buritan menuju area kerja utama. Area kerja utama (area nomor 3) digunakan anak buah kapal (ABK) untuk melakukan proses operasi penangkapan ikan dan untuk meletakkan gill net. Bagian haluan kapal (area nomor 4) terdapat reserve buoyancy haluan yang berfungsi untuk membantu kapal tetap mengapung saat terjadi kecelakaan. 


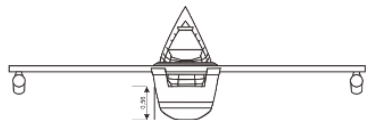

Tampak Belakang

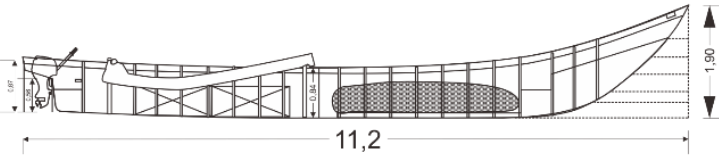

Tampak Samping

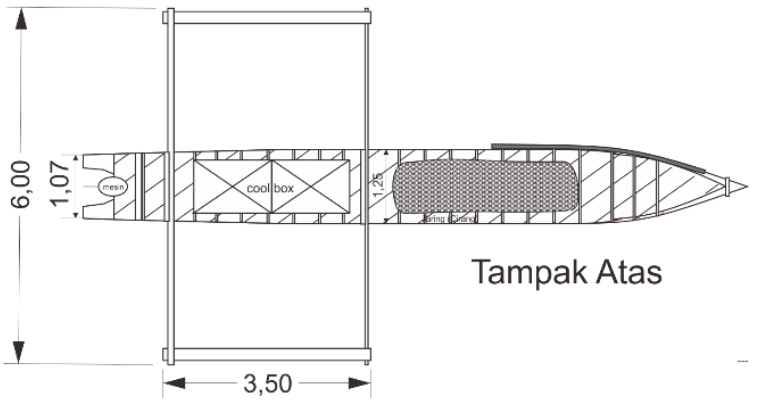

(a)

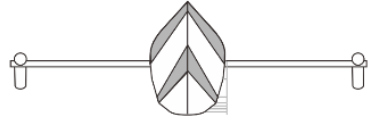

Tampak Depan
Ket:

Working Area

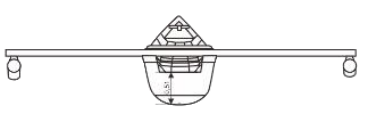

Tampak Belakang
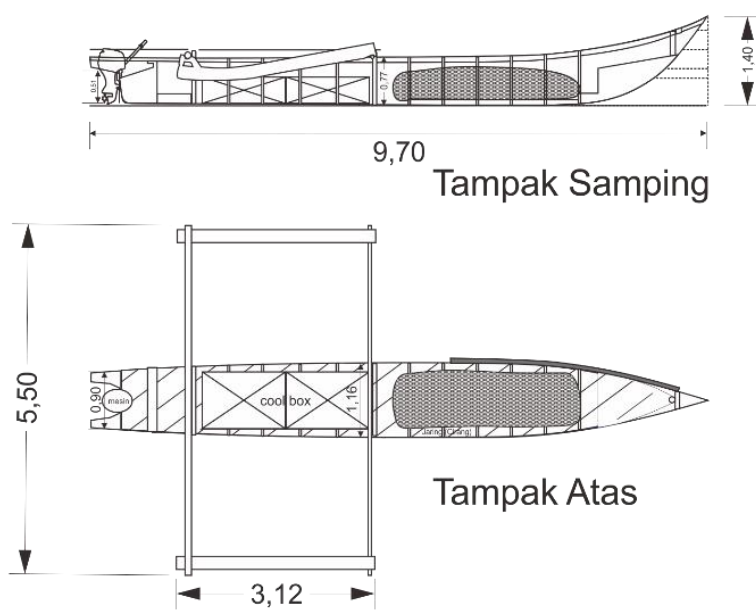

(b)

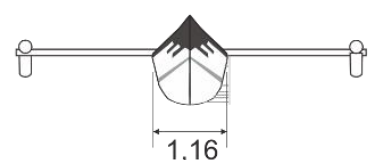

Tampak Depan

Gambar 5 General arrangement dan working area kapal di Kab. Cilacap

(a) Kapal bantuan KM. Nelayan 2018; (b) Kapal lokal

\section{PEMBAHASAN}

Kapal bantuan memiliki nilai B/D yang paling kecil dibandingkan dengan kapal lokal. Artinya, kapal bantuan memiliki tinggi kapal (D) yang lebih tinggi dibandingkan dengan $D$ pada kapal lokal. Dampaknya, daya tampung muatan pada kapal bantuan lebih besar jika dibandingkan dengan kapal lokal, akan tetapi kualitas stabilitasnya lebih rendah. Meskipun demikian, mengacu pada nilai rasio $B / D$, baik kapal bantuan dan kapal lokal secara umum memiliki kualitas stabilitas yang rendah sehingga kapal harus dilengkapi dengan katir (penyeimbang) untuk menjaga stabilitasnya.

Menurut Iskandar dan Pudjiati (1995) kapal dengan jenis alat tangkap static gear rentang nilai rasio dimensinya adalah L/B 2,83-
11,02, L/D 4,58-17,28 dan untuk nilai B/D 0,964,68 . Semua nilai rasio dimensi kapal sampel berada di dalam rentang nilai yang menjadi batas ambangnya. Oleh karena itu, kapal nelayan dan kapal bantuan masih sesuai untuk menggunakan alat tangkap jenis gill net maupun jenis static gear lainnya.

Sudut kemiringan linggi haluan kapal bantuan dan kapal lokal masing-masing yaitu 45,10 dan $45,96^{\circ}$. Keduanya memiliki sudut kemiringan antara garis tegak haluan dengan ujung linggi haluan lebih dari $45^{\circ}$, sehingga termasuk ke dalam jenis raked bow landai (Bangun et al. 2017). Kapal lokal memiliki sudut kemiringan linggi lebih besar dari kapal bantuan. Artinya, gelombang air yang dihasilkan oleh linggi kapal bantuan akan semakin rendah. Semakin landai sudut linggi kapal dapat berpengaruh pada se- 
makin rendah ketinggian gelombang yang dihasilkan ketika melaju (Noblesse et al. 2011).

Tinggi dudukan mesin pada linggi buritan kapal bantuan adalah $56 \mathrm{~cm}$ sedangkan pada kapal lokal rata-rata adalah $52 \mathrm{~cm}$. Hal ini menyebabkan baling-baling mesin motor tempel pada kapal bantuan tidak bekerja secara optimal di dalam air, akibatnya kecepatan kapal berkurang. Hal ini dikarenakan kecepatan kapal dipengaruhi oleh sudut poros baling-baling dan sudut poros berbanding lurus dengan jarak dari permukaan air, sudut yang lebih besar dihasilkan dari jarak yang lebih dalam (Kilmanun 2012).

Kasko pada kapal bantuan dan kapal lokal memiliki bentuk yang sama yaitu u-bottom. Perbedaannya terdapat pada kelengkungan badan kapal bagian haluan, khususnya pada batas waterline. Saat kapal melaju, hempasan air yang dihasilkan oleh kapal bantuan dapat mengenai nelayan di atas kapal, namun pada kapal lokal hempasan air dapat dibelokkan kembali ke permukaan air. Oleh karena itu, permukaan kapal yang terkena hempasan air juga lebih sedikit. Semakin sedikit permukaan kapal yang terkena tahanan oleh gelombang air, maka kecepatan kapal semakin baik (Fadillah et al. 2019).

Data hasil identifikasi menunjukkan bahwa secara umum kapal bantuan menyerupai kapal lokal. Akan tetapi masih terdapat beberapa kekurangan pada kapal bantuan yang menurut nelayan lokal belum dapat diterima dengan baik, sehingga tidak dapat digunakan secara langsung, meliputi:

\section{Dimensi utama kapal,}

Panjang kapal bantuan yang men-capai $11 \mathrm{~m}$ tergolong kapal motor tempel besar bagi nelayan lokal. Berdasarkan kebiasaan nelayan di galangan kapal Cilacap, jika panjang kapal 11 $\mathrm{m}$, maka lebar kapal mencapai 1,25-1,30 m dengan tinggi kapal 0,82-0,83 $\mathrm{cm}$ dan tinggi haluan kapal kurang lebih 1,45-1,50 m, namun tinggi haluan kapal bantuan mencapai 1,90 m. Haluan kapal yang terlalu tinggi pada kapal bantuan menutupi pandangan nahkoda dalam melihat jalur pelayaran. Hal ini akan meningkatkan risiko kecelakaan di laut, sedangkan berdasarkan pengalaman nelayan setempat, kapal dengan tinggi haluan 1,35-1,50 sudah mampu menghadang gelombang dengan baik pada jarak kurang lebih 5 mill dari home base. Kondisi ini sudah memenuhi rekomendasi keselamatan menurut Southeast Asian Fisheries Development Center (SEAFDEC 2014).

\section{Reserve buoyancy kapal}

Berdasarkan hasil pengamatan dapat dilihat reserve buoyancy haluan kapal bantuan terlalu miring (Gambar 2). Kondisi ini membahayakan nelayan untuk tergelincir saat sedang berkerja di haluan. Mengacu pada rekomendasi The Southeast Asian Fisheries Development Center (2014), kapal bantuan ini tidak sesuai dengan standar keselamatan untuk melindungi nelayan saat bekerja. Oleh karena itu, kemiringan reserve buoyancy haluan kapal harus lebih landai agar dapat digunakan untuk berkerja dan mengurangi risiko tergelincir.

Proses penangkapan mengharuskan nelayan untuk bergerak mundur saat sedang setting alat tangkap. Oleh karena itu, reserve buoyancy buritan kapal perlu diberi sekat untuk menghalau air masuk ke dalam kapal, namun pada kapal bantuan sekat pada reserve buoyancy buritan tidak ada (Gambar 3). Kondisi ini memungkinkan air akan mudah masuk ketika kapal berjalan mundur. Hal ini juga akan meningkatkan risiko kapal terisi oleh air dan mengganggu nelayan saat sedang bekerja.

\section{Faktor lain non-teknis desain}

Dari hasil wawancara nelayan dan juga pengamatan langsung pada kapal bantuan, terdapat faktor non teknis desain yang harus menjadi perhatian pemerintah dalam membuat kapal bantuan yaitu:

\section{a. Corak kapal}

Corak kapal merupakan ciri khas daerah mereka (Putra 2019), demikian juga di Kabupaten Cilacap. Corak kapal sebagai ciri khas dimana galangan kapal di buat. Corak menjadi nilai faktor sosial masyarakat dalam keindahan kapal sebagai kebanggaan pemilik kapal, namun corak kapal bantuan terkesan biasa dan tidak disesuaikan dengan kebiasaan nelayan Cilacap.

\section{b. Laminasi dan finishing kapal}

Ketebalan dan kekuatan lapisan kapal adalah faktor penting dalam pembuatan kapal fiberglass. Bibir kapal bantuan memiliki tebal 0,4 cm, sedangkan kapal lokal memiliki tebal $1,5 \mathrm{~cm}$, sehingga nelayan harus kembali melapisi ulang kapal bantuan. Selain itu, banyak resin yang mengeras tidak beraturan dan tajam belum diperhalus terlebih dahulu, sehingga faktor keamanan dan keselamatan bagi nelayan saat bekerja perlu lebih diperhatikan.

Ketidaksesuaian kapal bantuan dan kapal lokal menurut galangan lokal dapat terjadi karena pihak galangan tidak mengetahui kebiasaan serta detail terkait bentuk dan ukuran kapal yang digunakan nelayan setempat. Hal ini diakui oleh Dinas Perikanan Kabupaten Cilacap dan memang menjadi kendala setiap kapal bantuan 
yang dibuat bukan di galangan lokal. Oleh karena itu, agar kapal dapat diterima dengan baik oleh nelayan lokal, dalam pembuatannya sebaiknya melibatkan nelayan lokal atau dapat diserahkan kepada galangan lokal.

\section{KESIMPULAN}

Nilai rasio dimensi utama kapal bantuan dan kapal lokal di Kabupaten Cilacap berada di rentang nilai yang sesuai dengan kapal beralat tangkap static di Indonesia. Selanjutnya, linggi haluan keduanya berbentuk raked bow landai, linggi buritannya berbentuk transom stern dan bentuk kasko keduanya adalah u-bottom. General arrangement dan working area keduanya hampir sama, namun terdapat perbedaan pada kemiringan reserve buoyancy haluan, tinggi dudukan mesin, tidak adanya sekat di reserve buoyancy buritan dan jarak antar gading. Identifikasi perbedaan detail faktor teknis desain pada kapal bantuan dan kapal lokal menunjukkan bahwa kapal bantuan perlu direnovasi serta diadaptasi oleh nelayan lokal untuk mengurangi risiko kecelakaan nelayan di laut.

\section{SARAN}

Saran untuk penelitian selanjutnya adalah perlu dilakukan kajian terkait faktor sosial pada kapal lokal terkait karakteristik yang menjadi kearifan lokal, serta faktor keselamatan dan keamanan pada kapal bantuan.

\section{UCAPAN TERIMA KASIH}

Penulis mengucapkan terimakasih kepada Lembaga Pengelola Dana Pendidikan (LPDP-RI) yang telah mendanai dan mendukung penelitian ini.

\section{DAFTAR PUSTAKA}

Bangun TNC, Novita Y, Iskandar BH. 2017. Bentuk Linggi Haluan Kapal Penangkap Ikan (Kurang Dari $30 \mathrm{GT}$ ). ALBACORE. 1(2): 127-137.

Djunaedi A, Basuki MN. 2002. Perencanaan Pengembangan Kawasan Pesisir. J Teknologi Lingkungan. 3(3): 225-231.

Fadillah A, Manullang S, Irvana R. 2019. Stabilitas, Hambatan dan Olah Gerak Kapal Ikan Multi Purpose Net/Line Hauler 20 GT Berdasarkan Kajian Ukuran dan Bentuk
Kasko Kapal. Marine Fisheries. 10(2): 117128.

Fyson J. 1985. Design of Small Fishing Vessels. England (UK): Fishing News Book.

Iskandar BH, S Pujiati 1995. Keragaan Teknis Kapal Perikanan di Beberapa Wilayah Indonesia [laporan penelitian]. Bogor (ID): Institut Pertanian Bogor.

Juniarta HP, Susilo E, Primyastanto M. 2013. Kajian Profil Kearifan Lokal Masyarakat Pesisir Pulau Gili Kecamatan Sumberasih Kabupaten Probolinggo Jawa Timur. J ECSOFiM. 1(1): 11-25.

Kadir H, Rizal A, Laapo A. 2016. Analisis Tingkat Keberlanjutan Program Kapal Inkamina (30 GT) di Desa Labuan Bajo Kabupaten Donggala. J Sains dan Teknol Tadulako. 5(3): 54-64.

Kilmanun AD. 2012. Kajian Teknis Kecepatan Kapal Jukung di Ur Pulau Maluku Tenggara [tesis]. Bogor (ID): Institut Pertanian Bogor.

Lautetu LM, Kumurur VA, Warouw F. 2019. Karakteristik Permukiman Masyarakat pada Kawasan Pesisir Kecamatan Bunaken. $J$ Spasial. 6(1): 126-136.

Lungari FF, Dalekes RA. 2018. Karakteristik Dimensi Utama Perahu Katir "Pumpboat" di Enemawira dan Peta-Kepulauan Sangihe. JURNAL ILMIAH TINDALUNG. 4(1): 45-49.

Manopo AR, Masengi KWA, Pamikiran RDCH. 2012. Studi Pengaruh Bentuk Kasko pada Tahanan Kapal Pukat Cincin di Tumumpa, Bitung, dan Molibagu (Provinsi Sulawesi Utara). JITPT. 1(2): 63-68.

Mira. 2015. Atribut Penentu Keberhasilan Program Kapal Bantuan dalam Peningkatkan Kesejahteraan Nelayan. J PKS. 14(1): 3043.

Nahdyah N, Farhum A, Jaya I. 2014. Keragaman Jenis Kapal Perikanan di Kabupaten Takalar. J IPTEKS PSP. 1(1): 81-94.

Noblesse F, Delhommeau G, Yang C, Kim HY, Queutey P. 2011. Analytical Bow Waves for Fine Ship Bows with Rake and Flare. Journal of Ship Research. 55(1): 1-18.

Novita Y, Iskandar BH. 2008. Hubungan Antara Bentuk Kasko Model Kapal Ikan dengan Tahanan Gerak. Buletin PSP. 17(3): 315324.

Putra PKDNY. 2019. Desain Kapal Penangkap Ikan Berdasarkan Kearifan Lokal di Pelabuhan Perikanan Nusantara Brondong Jawa 
Timur [tesis]. Bogor (ID): Institut Pertanian Bogor.

Rukayah, Thaba A. 2018. Modus Ekspresi Kearifan Lokal Masyarakat Bugis: Suatu Kajian Elong Ugi dengan Perspektif Hermeneutika. Metalingua. 16(2): 257-272.

[SEAFDEC] Southeast Asian Fisheries Development Center (ID). 2014. Safety Recommendations for Decked Fishing Vessels of Less than 12 Metres in Length and Undecked Fishing Vessels IMO/FAO/ ILO. Jepang (JP): Japanese Trust Fund

Subagyo T. 2019. HNSI Sambas: Kapal Bantuan KKP Jarang Digunakan Nelayan. [internet]. [diunduh pada 20 Juli 2020]. Tersedia pada https://www.antaranews.com/berita/97503 6/hnsi-sambas-kapal-bantuan-kkp-jarangdigunakan-nelayan
Susanto A, Iskandar BH, Imron M. 2011. Evaluasi Desain dan Stabilitas Kapal Penangkap Ikan di Palabuhan ratu (Studi Kasus Kapal PSP 01). Marine Fisheries. 2(2): 213-221.

Trimulyono A, Amiruddin W, Purwanto ED, Sasmito B. 2015. Kajian Penggunaan Program Aplikasi Desain Kapal Tradisional pada Galangan Kapal Kayu di Kabupaten Batang. KAPAL. 12(3): 139-144.

Utomo B. 2010. Pengaruh Ukuran Utama Kapal Terhadap Displacement Kapal. TEKNIK. 31(1): 84-90.

Yulianto ES, Iskandar BH, Purwangka F, Mawardi W. 2013. Desain Perahu Fiberglass Bantuan LPPM IPB di Desa Cikahuripan, Kecamatan Cisolok, Sukabumi. BULETIN PSP. 21(1): 31-50 